\section{Degenerative Lumbar Spinal Stenosis}

Current Strategies in Diagnosis and Treatment

by Prof. Dr. med. Claudius Thomé, Dr. med. Frerk Meyer, PD Dr. med. Wolfgang Börm in volume 20/2008

\section{Effective Measure}

The article ends where the excitement begins for patients with inoperable lumbar spinal stenosis and for pain therapists. Analgesics as needed are not an option in this scenario. In my opinion, epidural therapy using water soluble corticoids and low dose local anesthetics (sequentially injected in a sterile manner at the level of the sacral cornua, provided that the patient's clotting mechanisms are intact). The postulated effective mechanism entails reduction of edema and creation of intraspinal space. This is a painless effective measure that I learnt from other anesthesiological pain therapists. I recommend evaluating this treatment in patients with lumbar spinal stenosis. We may need it ourselves one day!

DOl: 10.3238/arztebl.2008.0823a

Dr. med. Claudia Henneberg

Bahnhofstr. 18

69469 Weinheim, Germany

dr.c.henneberg@t-online.de

\section{Interdisciplinary Diagnostic System}

I agree with the authors that a multimodal therapeutic concept is required. The symptoms associated with lumbar spinal stenosis are multifactorial. In order to give targeted and appropriate treatment, a standardized interdisciplinary diagnostic setting is necessary — for example Sommerfeld's diagnostic system $(1,2)$. Functional morphological and psychosocial factors are investigated and assessed for their respective influence in the current disease process. Only in this way is it possible to define a clear indication for the components of complex treatment in disorders with a multifactorial origin; this is very much the case for operative procedures.

A fundamental principle of non-operative treatment is reduction of the lumbar lordosis. This principle was mentioned but not included in the algorithm in the article. "Optional physiotherapy" does not reflect its real importance as a therapeutic option. Insufficient muscular stabilization of the lumbar spine (core stabilization) is a crucial pathogenetic factor for the symptoms of lumbar spinal stenosis. Therapy therefore needs to focus on improving core stabilization, to develop its activation, stamina, and strength.

Neurophysiological physiotherapeutic techniques, training therapy, and targeted customized exercise programs are used to this end. In a second step, activities of everyday life need to be practiced.

Accompanying analgesic medication should be given according to each drug's mechanism of action: anti- inflammatories for the anti-edematous effect, analgesics to reduce myalgias (by reducing the pain reflectory inhibition of muscle activation), appropriate medical if neuropathic pain is present, reacting to exacerbations of pain.

Interventional (3) and surgical procedures should aim to stabilize the muscles and avoid pain related impairments to strength and distances walked.

If this approach is pursued methodically then the human body is able to compensate to an astonishing degree, even in a scenario of pronounced degenerative stenosis of the lumbar spinal canal. Even if symptoms are severe, the initial therapeutic approach should always be an intense, non-surgical one (3).

DOl: 10.3238/arztebl.2008.0823b

\section{REFERENCES}

1. Niemier K, Seidel W, Ritz W, Pioch E, Werin A: Introduction and Evaluation of a Multiprofessional Assessment System for the Differential Diagnosis of Chronic Musculoskeletal Pain Syndromes. JOM 2005; 27: 71-80.

2. Niemier K, Ritz W, Seidel W : Funktionelle muskuloskeletale Diagnostik. Manuelle Medizin 2007; 45: 123-7.

3. Theodoridis T, Krämer J, Kleinert H: Konservative Behandlung der lumbalen Spinalkanalstenose - eine Übersicht. Z Orthop Unfall 2008; 146: 75-9

Dr. med. Kerstin Engel

Dr. med. Wolfram Seidel

Sana Kliniken Sommerfeld

Klinik für Manuelle Medizin

Fachkrankenhaus für nichtoperative Orthopädie

und Schmerzmedizin

16766 Kremmen, Germany

k.engel@sana-hu.de

\section{In Reply:}

In accordance with the algorithm featured in our article, patients with lumbar spinal stenosis are initially treated conservatively. A multitude of conservative therapeutic modalities are available, and we thank your correspondents for their contributions. However, a general algorithm does not leave room for detail. Our review article aimed to present current scientific knowledge according to the criteria of evidence based medicine, to enable readers to diagnose the condition more easily and to provide evidence based decision aids for treating it. Engel and Seidel propose special physiotherapeutic concepts as a fixed component in the treatment of lumbar spinal stenosis. However, unfortunately there is thus far no proof that conservative therapeutic concepts are superior to other measures, so we were not able to deduce such recommendations for our article. Study results exist for the operative treatment pathway, but not for conservative treatment (1). Hence the effectiveness of the different therapeutic options is still not clear, and further studies are highly desirable.

Engel and Seidel want to apply a standardized diagnostic instrument to a multimodal conservative therapeutic 
concept and recommend a system developed by themselves. Like most of the published data collection systems, however, theirs was conceived for general skeletal disorders and patients with chronic pain and a high prevalence of psychosocial disorders (2). Although the pretherapeutic assessment of patients with spinal disorders seems to make sense, there is thus far no widely used diagnostic system, nor has it ever been shown that using such a system really does improve the treatment result.

The concluding recommendation of attempting nonsurgical treatment as an initial measure is consistent with our algorithm. The acute paralyses or intolerable intractable pain that may necessitate immediate surgery are rare with lumbar spinal stenosis (1) and are mostly caused by associated disc prolapse. Of course symptoms may improve after conservative therapy even in cases of radiologically massive stenosis. But if several months of conservative treatment do not yield sufficient improvement then surgery is indicated.

Henneberg in her letter mentions epidural injection of corticoids and local anesthetics for patients with inoperable spinal stenosis. Although owing to anesthesiological progress, only few patients are regarded as inoperable, we are in support of her suggestion to evaluate this injection therapy in lumbar spinal stenosis. Unfortunately, epidural injection of corticoids has thus far been undertaken only in patients with unilateral lumbar root compression $(1,3)$ and not in patients with lumbar spinal stenosis. As long as the sustained effectiveness or superiority of this treatment option vis-à-vis others has not been shown, non-licensed treatments can often not be integrated into evidence based treatment guidelines, especially if they are invasive measures and as such not harmless.

DOI: 10.3238/arztebl.2008.0824

\section{REFERENCES}

1. Theodoridis T, Krämer J, Kleinert $\mathrm{H}$ : Konservative Behandlung der lumbalen Spinalkanalstenose - eine Übersicht. Z Orthop Unfall 2008; 146: 75-9.

2. Niemier K, Ritz W, Seidel W: Funktionelle muskuloskeletale Diagnostik. Manuelle Medizin 2007; 45: 123-7.

3. Ng L, Chaudary N, Sell P: The efficacy of corticosteroids in periradicular infiltration for chronic radicular pain: a randomized, double-blind, controlled trial. Spine 2005; 30: 857-62.

\section{Prof. Dr. med. Claudius Thomé}

Neurochirurgische Klinik

Universitätsklinikum Mannheim

Medizinische Fakultät Mannheim der Universität Heidelberg

Theodor-Kutzer-Ufer 1-3

68167 Mannheim, Germany

claudius.thome@nch.ma.uni-heidelberg.de

\section{PD Dr. med. Wolfgang Börm}

Neurochirurgische Klinik

Ev. Luth. Diakonissenanstalt Flensburg

Marienhölzungsweg 4

24939 Flensburg, Germany

neurochirurgie@diako.de

Dr. med. Frerk Meyer

Klinik für Neurochirurgie

Evangelisches Krankenhaus Oldenburg

Steinweg 13-17

26122 Oldenburg, Germany

dr.frerk.meyer@evangelischeskrankenhaus.de

\section{Conflict of interest statement}

The authors of all the letters and of the reply declare that no conflict of interests exists according to the Guidelines of the International Committee of Medical Journal Editors. 